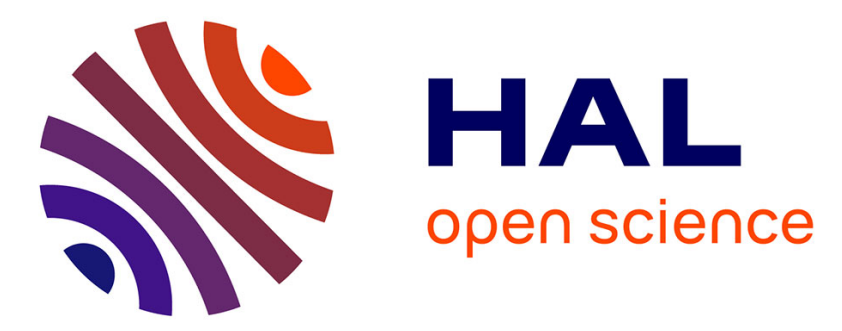

\title{
Investigation on Adhesion, Interphases, and Failure Behaviour of Cyclic Butylene Terephthalate (CBT)/Glass Fiber Composites
}

Edith Mäder, Shang-Lin Gao, Rosemarie Plonka, Jing Wang

\section{- To cite this version:}

Edith Mäder, Shang-Lin Gao, Rosemarie Plonka, Jing Wang. Investigation on Adhesion, Interphases, and Failure Behaviour of Cyclic Butylene Terephthalate (CBT)/Glass Fiber Composites. Composites Science and Technology, 2007, 67 (15-16), pp.3140. 10.1016/j.compscitech.2007.04.014 . hal00498986

\section{HAL Id: hal-00498986 https://hal.science/hal-00498986}

Submitted on 9 Jul 2010

HAL is a multi-disciplinary open access archive for the deposit and dissemination of scientific research documents, whether they are published or not. The documents may come from teaching and research institutions in France or abroad, or from public or private research centers.
L'archive ouverte pluridisciplinaire HAL, est destinée au dépôt et à la diffusion de documents scientifiques de niveau recherche, publiés ou non, émanant des établissements d'enseignement et de recherche français ou étrangers, des laboratoires publics ou privés. 


\section{Accepted Manuscript}

Investigation on Adhesion, Interphases, and Failure Behaviour of Cyclic Butylene Terephthalate $\left(\mathrm{CBT}^{\circledR}\right)$ /Glass Fiber Composites

Edith Mäder, Shang-Lin Gao, Rosemarie Plonka, Jing Wang

PII: S0266-3538(07)00172-8

DOI: 10.1016/j.compscitech.2007.04.014

Reference: CSTE 3673

To appear in: Composites Science and Technology

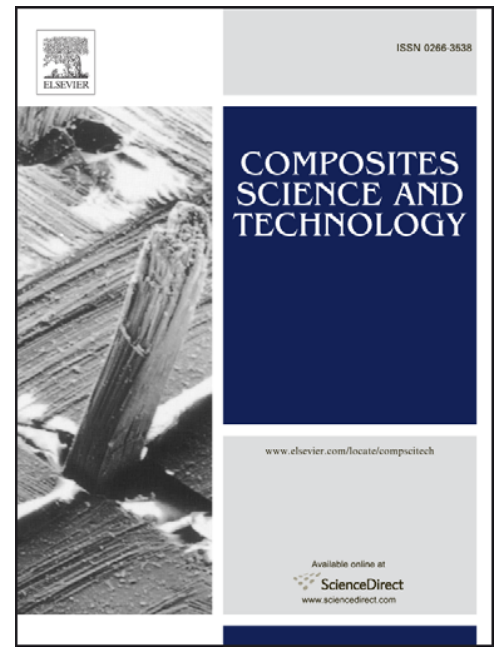

Received Date: $\quad 21$ November 2006

Revised Date: $\quad 20$ April 2007

Accepted Date: $\quad 23$ April 2007

Please cite this article as: Mäder, E., Gao, S-L., Plonka, R., Wang, J., Investigation on Adhesion, Interphases, and Failure Behaviour of Cyclic Butylene Terephthalate (CBT $\left.{ }^{\circledR}\right) /$ Glass Fiber Composites, Composites Science and Technology (2007), doi: 10.1016/j.compscitech.2007.04.014

This is a PDF file of an unedited manuscript that has been accepted for publication. As a service to our customers we are providing this early version of the manuscript. The manuscript will undergo copyediting, typesetting, and review of the resulting proof before it is published in its final form. Please note that during the production process errors may be discovered which could affect the content, and all legal disclaimers that apply to the journal pertain. 


\title{
Investigation on Adhesion, Interphases, and Failure Behaviour of Cyclic Butylene Terephthalate $\left(\mathrm{CBT}^{\circledR}\right) /$ Glass Fiber Composites
}

\author{
Edith Mäder ${ }^{1 *}$, Shang-Lin Gao ${ }^{1}$, Rosemarie Plonka ${ }^{1}$, Jing Wang ${ }^{2}$ \\ ${ }^{1}$ Leibniz Institute of Polymer Research Dresden, Hohe Str. 6, D-01069 Dresden, Germany \\ ${ }^{2}$ Cyclics Corporation, 2135 Technology Drive, Schenectady, NY 12308, U.S.A.
}

\begin{abstract}
Interphases exist in hybrid materials and significantly influence their mechanical performance. To find a bridge between the microscopic and macroscopic mechanical properties, this work investigates the microscopic nature of glass fiber surfaces and glass/CBT interphases in terms of topography, fractography, and adhesion properties. The variations in glass fiber surface properties result from the different sizings. Using the single fiber pull-out test, AFM, and zeta potential tests, it is shown that the interfacial bond strengths in CBT resin composites can vary depending on the kind of sizing formulation and properties. The greatest adhesion strength is achieved by aminosilane sizings with epoxy resin film former. The surface roughness of the fibers can be varied by sizings with different content and zeta potential values, which has no significant contribution to interphase adhesion strength from 'mechanical interlocking'. For the systems with film formers, cohesive failure occurs and similar values of both interfacial adhesion strength, $\tau_{d}$, and fracture energy release rate, $G_{i c}$, are obtained, in which $\tau_{d}$ approaches the shear yield strength of CBT matrix. A further enhancement of interfacial adhesion is limited by the mechanical properties and the non-homogeneous microstructure of CBT resin due to the less-than-perfect CBT polymerization.
\end{abstract}

Keywords: $\quad$ A. Polymer-matrix composites; Glass fibers ; CBT

B. Interfacial strength;

D. Fractography

\footnotetext{
* Corresponding author: Dr. Edith Mäder

Phone: 03514658305

Fax: 03514658362

e-mail: emaeder@ipfdd.de
} 


\section{INTRODUCTION}

The mechanical properties of composites can vary depending on the interphases between fibers and bulk matrix. One effective way of creating an in terphase layer on the nanoscale and in turn, controlling composite properties, is using surface sizing for glass fibers. Glass fiber sizings are normally multi-component systems mainly consisting of silane coupling agents, film formers, and lubricants, which fulfill both adhesion and wetting relevant requirements in composites and enable to prevent damages of the glass fibers during the processing. It was also demonstrated that a suitable combination of silane coupling agents and film formers can improve fiber strength by healing surface flaws, which in turn, can be effectively utilized under an optimum bonding to improve composites properties.

In continuous-fiber/matrix laminated composites, the experimental results indicated that slightly varied interphases could lead to significantly altered composite mechanical performance. The interfacial adhesion strength can, in general, be dominated by chemical (e.g. covalent) bonding, by physical (e.g. polar) interactions, by mechanical (e.g. roughening) keying, by diffusion of components of the pretreatment into the sizing (e.g. interpenetrating networks), or by an intricate combination of these. It is obvious in fibrous composite materials that en ergy is dissipated during crack initiation and propagation by a multiplicity of microfracture events like fiber fracture, matrix cracking, fiber/matrix debonding, delamination, interfacial breakdown, fiber and matrix relaxation. Therefore, it is necessary to distinguish the different fiber/matrix systems like brittle or ductile matrix and strong or weak fiber/matrix adhesion, generated by sizing and matrix modification.

The high viscosity of thermoplastic matrices hamper fiber impregnation. This can be overcome by using low viscous polymeric precursors such as cyclic butylene terephthalate (CBT ${ }^{\circledR}$ resin), which can polymerize to form a thermoplastic matrix after fiber impregnation. CBT res in, is oligomers of polybutylene terephthalate (PBT) resin that polymerizes reactively like thermosets but has the material properties of thermoplastics. CBT resin is solid at room temperature and, when heated, is fully molten above $160^{\circ} \mathrm{C}$, with a viscosity in the range of $150 \mathrm{MPa}$ s. It's viscosity drops to below $20 \mathrm{MPa} \mathrm{s}$ at $180^{\circ} \mathrm{C}$. When mixed with specific tin or titanium polymerization catalysts the macrocyclic PBT rings open and connect (polymerize) to form high molecular weight PBT thermoplastic without exotherm or off-gassing. Full polymerization can occur in 10's of seconds or many minutes depending on the polymerization temperature and type of catalyst used. The combination of low viscosity and rapid polymerization of CBT resin allows for fast processing in many different applications. In addition, the initial water-like viscosity allows rapid and excellent wet-out of filler reinforcements and high filler loadings can be achieved at large scale component 
processing. It was believed that CBT resin is compatible with most fillers and additives currently used with PBT. However, the interfacial adhesion between CBT resin and glass fiber and the fracture mechanism remain unclear.

The major objective of this work is to investigate the effects of organic sizings, usually applied on glass fiber surfaces, on the adhesive interaction with CBT resin. For the evaluation of the effectiveness of fiber surface sizings, the results of single fiber pull-out tests are considered in comparison to acidic and/or basic groups created by the sizings. Besides good adhesion strength, a negative influence of soluble sizings on the polymerization process has to be avoided. To understand the action of the toughening mechanisms and to increase their effectiveness of composites, it is necessary to study in detail the critical interphase energy release rate, $G_{i c}$, which is related to the initiation of a crack. Special emphas is is placed on the local characterization of the fiber surface topography, interphase mechanical properties and fracture behaviour, tempting to correlate the fracture surface morphology of pulled-out single fibers to micro-mechanical properties.

\section{EXPERIMENTAL}

\subsection{Designation of model glass fiber systems}

Several glass fiber samples were spun and continuously sized at IPF: unsized, $0.5 \mathrm{wt} \%$ aminosilane/epoxy based film former sized, $0.5 \mathrm{wt} \%$ epoxysilane/epoxy bas ed film former sized, $0.5 \mathrm{wt} \%$ methacrylsilane/epoxy based film former sized, $1.0 \mathrm{wt} \%$ epoxysilane/epoxy based film former sized and $0.5 \mathrm{wt} \%$ epoxysilane/urethane based film former sized. Specifically, designation of model glass fibers for CBT, sizing formulations developed, and sizing contents are given in Tab. 1. A comparison is also made with a commercial CBT-compatibly sized glass fiber (CBT2).

\subsection{Surface characterization}

An AFM (Digital Instruments D 3100, USA) was used as a fiber surface imaging tool. The topography of samples was studied in tapping mode at resonant frequency of approximately 300 $\mathrm{kHz}$, spring constant of the cantilever with n-type silicon tip: 38 to $60 \mathrm{~N} / \mathrm{m}$, images of $512 \times 512$ pixels, scanning frequency at $1 \mathrm{~Hz}$ per row of pixel. In addition, the failure surface of pulled-out fibers were revealed by AFM surface topography. Specimens were prepared by fixing separate short fibers on a glass plate, within a thin layer of pre-coated epoxy at the bottom side of the fiber (Fig.1). Roughness parameters derived from ASME B46.1 are calculated based upon the following definitions. Image mean roughness $\left(R_{a}\right)$ is the arithmetic average of the absolute values of the surface height deviations, $Z_{j}$, measured from the mean plane within the cursor box. Maximum height roughness $\left(R_{\max }\right)$ is the difference in height between the highest and lowest points on the cross-sectional profile relative to the centre line over the length of the profile. 
Electrokinetic investigations by an Electrokinetic analyser, EKA (A. Paar, AU, [1]) allow the estimation of both type and amount of dis sociable surface functional groups on the fiber surfaces, as well as predicting adsorption processes influenced by interaction forces at the surface. The zeta potential is the voltage difference between a plane which is a short distance from the particle surface and the solvent beyond the double layer. Streaming potential measurements revealed different zeta potential-pH dependence due to acidic and/or basic groups created by the sizings and the interaction between them at fiber surface layer and the environment.

\subsection{Interfacial a dhesio $n$ characterization}

The pre-polymers used in this study were the catalyzed cyclic butylene terephthalate oligomers (XB3-CA4 $\mathrm{CBT}^{\circledR}$ resin) supplied by Cyclics Corporation. We assemble the fiber and $\mathrm{CBT}^{\circledR}$ resin in a closed box (Fig.2) for embedding, then samples are heated to $100^{\circ} \mathrm{C}$ under argon purge gas for $30 \mathrm{~min}$ to dry the resin. Next, the resin was rapidly heated to $200^{\circ} \mathrm{C}$. The fiber was embedded in the resin for $60 \mathrm{~min}$ under $200{ }^{\circ} \mathrm{C}$ to polymerize the oligomers to PBT. The samples marked in Tables 2 and 4 were firstly heated at $80^{\circ} \mathrm{C}$ under argon purge gas for $30 \mathrm{~min}$ to dry the resin and then were rapidly heating to $190^{\circ} \mathrm{C}$ for $30 \mathrm{~min}$ to finish the polymerization. All sample were stored in desiccator (silica) before pull-out test. After pull-out tests these samples were undertaken GPC analysis to verify degree of polymerization.

The different interphases in the vicinity of the CBT matrix/glass fiber interface were evaluated by single fiber pull-out test. Samples were made by a self-made sample preparation equipment designed and constructed earlier at IPF. The pull-out apparatus allowed investigators to obtain force-displacement curves of the single fiber composites under quasi-static conditions with a loading rate of $0.01 \mu \mathrm{m} / \mathrm{s}$ at ambient conditions. The free fiber lengths were kept as short as possible, and the installation was stiff enough to discern the "kinks" in force-displacement curves which indicated the onset of debonding. The diameter of the fibers was measured immediately after the pull-out testing at the previously embedded fiber end using an optical microscope.

For the experimental data treatment the latest approaches are used to determine adhesion strength, $\tau_{d}$, frictional strength (also referred as interfacial stress in debonded regions), $\tau_{f}$, and critical energy release rate, $G_{i c}$ [2]. To characterize fiber-matrix adhesion, $\tau_{d}$ and $G_{i c}$, are calculated from the debond force value, $F_{d}$, at which interfacial debond ing starts in a single fiber model specimen during pull-out (this corresponds to a kink point in the force-displacement curve, see Fig. 8 in ref [3], using theoretical models described in detail in Ref. [4]. The interfacial frictional stress, $\tau_{f}$, was determined from $F_{d}$ and $F_{\max }$ values using the procedure based on the expression of pull-out force as a function of the crack length [5]. We calculated an energy parameter which characterizes 
debonding the fiber from the polymer matrix, namely, the critical interphase energy release rate, $G_{i c}$. The debond force, $F_{d}$, is related to $G_{i c}$ by the equation [6]:

$$
F_{d}=\pi r_{f}^{2}\left(-p+\sqrt{p^{2}-q\left(G_{i c}\right)}\right),
$$

where $p$ and $q\left(G_{i c}\right)$ are terms depending on fiber and matrix mechanical properties and specimen geometry; their expressions and the derivation are given in [5].

\section{RESULTS AND DISCUSSION}

\subsection{Surface properties of glass fiber}

We first investigated the fiber surface chemical and morphological characteristics. The zeta potential depends on the surface charge density and the double layer thickness. The surface charge density, in turn, depends on the concen tration of "potential-determining ions" in the solvent-ions that have a particular affinity for the surface. In many systems, the $\mathrm{H}^{+}$ion is potential-determining, and so the zeta potential depends on $\mathrm{pH}$. The zeta potential is positive for low $\mathrm{pH}$ values and negative for high $\mathrm{pH}$ values. The $\mathrm{pH}$ at which the zeta is zero is the isoelectric point (IEP) of the colloid. The IEP is a property of the particle surface.

As shown in Fig. 3, the streaming potential measurements indicated that the untreated glass fiber surface possesses a negative zeta potential and IEP of about $\mathrm{pH} 3$. In addition, negative zeta potential and IEP values are also in the acidic region for cases of CBT2, CBT 11 to 14. Clearly, the chemical nature of the fiber surface is dominated by acidic functional groups. For sized fibers containing different film formers in addition to epoxysilane coupling agent (i.e. CBT11/14 compared to CBT13, Fig.3a), the IEP's are shifted to higher pH-values of CBT13 (polyurethane film former with carbamite groups and NH-groups) than that of CBT11/14 (epoxy resin). The lowest IEP values were found for the cases of CBT 1 (unsized) and CBT 11,12,14 which have methacrylsilane and epoxysilane sizings with epoxy film former. Interestingly, the commercial CBT 2 also shows acidic behaviour with higher IEP values in comparison with the others in Fig.3a, which might be due to the use of cationic surfactants, although the exact formulation is unknown, IR-investigation indicated epoxy based film former.

In contrast, the IEP for APS-sized (CBT7) and APS/EP sized (CBT4 and 10) glass fibers was detected at $\mathrm{pH} \sim 9$, and, similarly, the IEP of CTB 4 and 10 (Aminosilane and epoxy resin film former) is determined at a $\mathrm{pH}$ of 8 . It indicates that basic amino-groups dominate the fiber surface. Amino groups are available at the interface for adhesional bonds with the polymer matrix. Depending on the fiber treatment conditions, both humidity and/or temperature, the IEP could also be shifted to smaller values, as demonstrated previously [3]. It was expected that the glass fiber with the different surface polarity would influence the interfacial adhesion performances which will be further presented in next part of this work. 
Additional information can be derived from the zeta potential value. Generally, the zeta potential is an expression of the chemical nature (acidity, basicity) and the topography of the outermost surface layer. When two charged particles come so close that their double layers overlap, they repel each other. The strength of this electrostatic force depends on the zeta potential. A high absolute zeta potential value will prevent particle-particle agglomeration keeping the dispersion uniform and free flowing in the emulsion, thus high absolute zeta potential value is mostly desired for the forming of a uniform and steady suspension. If the zeta potential is too small (typically less than about $25 \mathrm{mV}$ in magnitude), the repulsive force will not be strong enough to overcome the Van der Waals attraction between the particles, and they will begin to agglomerate. If the emulsion is concentrated and unstable, these agglomerates form networks, and the colloid turns into a paste. The sizings for fiber surface are multi-component systems in an aqueous dispersion, mainly consisting of silane coupling agents, film formers, and lubricants. Their particle size distribution can vary in the range of 100 to $900 \mathrm{~nm}$. The measured zeta potential value of fiber surface is a result of either stable or unstable coating dispersions during sizing process, which causes different topography of fiber surface. It is observed that the representative AFM microphotographs in Figs. 4 and 5 are markedly different depending on the formulation of sizings. The average and maximum roughness parameters of every system are presented in Fig. 6. As expected, we observed relatively neat and smooth surfaces $\left(R_{a}<4 \mathrm{~nm}, R_{\max }<50 \mathrm{~nm}\right)$ on unsized glass fibers (CBT1) and sized fiber without film former (CBT7). Interestingly, it can be seen that the sized fibers with film formers (CBT2, 4 and 10) also show smooth surfaces, which is in sharp contrast to the other systems with different film formers (CBT 11-14), where non-un iform sizings with significantly high surface roughness values $\left(R_{a}, 10 \sim 30 \mathrm{~nm} ; R_{\max }, 100 \sim 300 \mathrm{~nm}\right)$ were found due to the increased sizing/film former content and absence of surfactant which is essentially consistent with their low zeta potential. It is suggested that the high zeta potential of CBT 4, 7 and 10, as aforementioned, might prevent particle-particle agglomeration and keep the sizing dispersion uniform and free flowing, in turn, resulting in smooth sizings.

\subsection{Interface adhesion properties}

To specify the effect of fiber surface properties on the interphase adhesion behaviour, micromechanical tests of model composites were investigated by means of the single fiber pullout test. The calculated results of interfacial adhesion strength, $\tau_{d}$, frictional strength, $\tau_{\text {; }}$, and critical energy release rate, $G_{i c}$ for all fiber-matrix systems are presented in Table 2. The highest adhesion strength is achieved by CBT 10 with aminosilane and epoxy resin film former sizings, while the lowest values are found, as expected, for the unsized fiber system. The CBT7 fiber (APS sizing without film former) also shows low interfacial adhesion and fracture energy. For other 
systems with different sizings and conditions of polymerisation, a significant change of the adhesion characteristics in terms of $\tau_{d}, \tau_{f}$, and $G_{i c}$ cannot be detected. Most values of $\tau_{d}$ are very close to CBT resin's shear strength $\left(\sigma_{\mathrm{y}}=\sigma_{0} / 3^{1 / 2}=31 \mathrm{MPa}\right)$, suggesting in these cases the interphase polymer chain experiences shear yielding and failure. Table 3 shows molecular weights determined by gel permeation chromatography (GPC). Conversions of polymerisation are strongly dependent on the conditions of polymerization, while the measured molecular weights do not directly correlate. Most of the conversions were around $85 \%$ (conditions of polymerisation: heating $80^{\circ} \mathrm{C}$ under argon purge gas for $30 \mathrm{~min}$; rapid heating to $190^{\circ} \mathrm{C}, 30 \mathrm{~min}$ polymerization at $190^{\circ} \mathrm{C}$ ) that means there were still about 10 to $15 \%$ CBT ${ }^{\circledR}$ resin oligomers. The molecular weights were not high compared to the same resin polymerized under improved conditions for preparing single fiber model composites adapted to the equipment (heated to $100^{\circ} \mathrm{C}$ under argon purge gas for $30 \mathrm{~min}$; rapid heating to $200^{\circ} \mathrm{C}, 60 \mathrm{~min}$ polymerization at $200^{\circ} \mathrm{C}$, cf. chapter 2.3 ) which generally reaches above $60 \mathrm{~kg} / \mathrm{mol}$ number average molecular weight. The lower results might be due to the insufficient drying of the resin and heat transfer in the specimen preparation set-up shown in Fig 2. The interphase adhesion properties of this CBT/glass fiber systems are lower than those of polar thermoplastic matrix composites like Nylon 6.6/glass or polycarbonate/glass and thermoset systems like epoxy/glass fiber or epoxy/carbon fiber $\left(\tau_{d}>90 \mathrm{MPa}, G_{i c}>40 \mathrm{MPa}\right)$ $[7,8]$. Usually, the interfacial adhesion strength of thermoplastic matrix composites is relatively low, compared to that of thermoset matrix composites. The important reasons of the low interfacial adhesion may be due to the low conversion of $\mathrm{CBT}{ }^{\circledR}$ resin. The $\mathrm{CBT}$ oligomer is not strong enough to provide mechanical bonding between the fibers and the matrix. Low molecular weight PBT with high oligomer content cannot provide good mechanical properties. Another important reason might be due to the non-homogeneous morphology of CBT resin polymerized under $190^{\circ} \mathrm{C}$ to $200^{\circ} \mathrm{C}$. Under such polymerization temperature, the CBT polymerizes while crystallizes that leads to generate high crystallized PBT. The large and perfect crystals together with a low density of tie molecules, resulting from isothermal and simultaneous polymerisation and crystallisation, might cause both interphase and polymer brittleness. This interphase brittleness could be enhanced by partly soluble sizings.

\subsection{Interface fracture energy and surface roughness}

Further insight can be obtained from the failure surface observation. The representative AFM microphotographs (Figs. 7, 8) are apparently different for the fibers after pull-out tests in comparison with the original states (Figs. 4, 5). The average roughness before and after pull-out tests are presented in Fig. 9 and Table 4 together with IEP and interfacial adhesion values. Overall, the roughness for all systems increases after pull-out. Figs. 7a and d show that the surface 
topography of CBT1 (unsized) and CBT 7 (APS sized) consists of some small patches on relatively smooth fiber surface, suggesting the failure crack propagation along the interface very close to fiber surface. For these two cases, the observation is consistent with their low interfacial adhesion strength and fracture energy. As to the other systems, however, the fracture surfaces are extensively covered with the sizing/CBT matrix material. In other words, cohesive failure occurs and the polymer near the fiber appears to have been extensively stretched during fiber pull-out. Therefore, similar values of both in terfacial adhesion strength, $\tau_{d}$, and fracture energy release rate, $G_{i c}$, are obtained, in which $\tau_{l}$ approaches the shear yield strength of CBT matrix. This observation implies the CBT resin had chemical reactions with the sizing functional groups during its polymerization. This observation also implies that a further enhancement of interfacial adhesion is limited by the mechanical properties of CBT resin. With better polymerized CBT resin, i.e. better conversion and molecular weight, it is possible to reach higher values of both interfacial adhesion strength, $\tau_{d}$, and fracture energy release rate, $G_{i c}$. It is interesting to see that variation ratio of roughness before and after pull-out is strongly dependent on the values of as-received samples. Specifically, the higher the roughness of as-received samples the lower is the variation ratio of roughness after pull-out, and vice versa, being likely to result from similar interphase fracture mechanisms associated with the brittle failure of CBT resin.

Overall, injecting low viscous thermoplastic prepolymers into a fiber preform to produce textile reinforced thermoplastics seems to be very promising since it combines both the advantages of thermoplastics and the ease of impregnation of thermoset resins. However, the mechanical properties of the glass fiber reinforced CBT resin can be significantly influenced by the in terfacial adhesion properties. The adhesion strengths are associated with the reactions between the CBT resin and sizing functional groups, crystallinity of the PBT thermoplastic, and mechanical properties of CBT resin. To increase the values of both interfacial adhesion strength, $\tau_{d}$, and fracture energy release rate, $G_{i c}$, future work is suggested to be conducted by nanostructuring interfaces [9] and polymerizing CBT resin under the temperature above PBT melt temperature (around $225^{\circ} \mathrm{C}$ ) and cooling down the polymer rapidly with will less crystalllinity of PBT.

\section{CONCLUSION}

Single fibre pull-out tests, AFM surface topography imaging, and zeta potential tests highlighted sizings consisting of aminosilane and epoxy film former to improve interfacial interaction in terms of interfacial adhesion strength and critical energy release rate for model CBT glass fiber systems. The origin of these best interfacial adhesion parameters is revealed by isoelectric points at a $\mathrm{pH}$ of 8. This data indicates most reactive alkaline amino-groups dominating the fiber surface and are available at the interface for adhesional bonds with the polymer matrix. It is particularly important 
for producing smooth coatings by controlling zeta potential value. By increasing the polymerisation temperature the higher mobility of the polymer chains enabled enhanced bond formation and led to improved interfacial parameters. Results of very sensitive pull-out and fracture surface tests on single fibre composites must be up-scaled to real composites.

\section{ACKNOWLEDGEMENT}

The authors are indebted to Dr. Tohru Takekoshi for exact determination of molecular weight distributions, Alma Rothe and Anja Caspari for single fiber pull-out testing and Zetapotential measurements, respectively.

\section{REFERENCES}

1. Grundke K, Michel S, Eichhorn KJ, Beyerlein D, Bayer T. Influence of chemical interactions on the macroscopic spreading of a maleic anhydride copolymer melt. Macromol. Chem. Phys. 2002;203:937-946.

2. Zhandarov S, Pisanova E, Mäder E. Is there any contradiction between the stress and energy failure criteria in micromechanical tests? Part II. Crack propagation: Effect of friction on force-disp lacement curves. Compos In terfaces 2000;7:149-175.

3. Plonka R, Mäder E, Gao SL, Bellmann C, Dutschk V, Zhandarov S. Adhesion in epoxy/glass fiber composites influenced by aging effects on sizings. Composites A., $2004 ; 35: 1207-1216$.

4. Zhandarov S, Mäder E. Characterization of fiber/matrix interface strength: applicability of different tests, approaches and parameters. Composite Science and Technology, $2004 ; 65: 149-160$.

5. Nairn JA. Analytical fracture mechanics analys is of the pull-out test including the effects of friction and thermal stresses. Adv Compos Lett 2000;9:373-383.

6. Gao SL, Mäder E, Zhandarov S. Carbon fibers and composites with epoxy resins: Topography, fractography and interphases. Carbon 2004;42:515-529.

7. Zhandarov S, Gorbatkina Yu, Mäder E. Adhesional pressure as a criterion for interfacial failure in fibrous microcomposites and its determination using a microbond test. Composite Science and Technology 2006;66:2610-2628.

8. Mäder E, Gao SL, Plonka R. Static and dynamic properties of single and multi-fiber/epoxy composites modified by sizings. Composite Science and Technology 2007;67:1105-1115.

9. Gao S.L, Mäder E, Plonka R. Nanostructured coatings of glass fibers: Improvement of alkali resistance and mechanical properties. Acta Materialia, 2007;55:1043-1052. 
Table 1. Glass fibre designation, sizing formulations and sizing contents

\begin{tabular}{|c|c|c|}
\hline Designation & Sizing formulation & Sizing content [wt\%] \\
\hline CBT 1 & unsized fiber & - \\
\hline CBT 2 & Commercial fiber & 0.44 \\
\hline CBT 4 & $\begin{array}{l}\text { APS ( } \gamma \text {-aminopropyl triethoxy silane })+ \text { epoxy res in film } \\
\text { former }\end{array}$ & 0.48 \\
\hline CBT 7 & APS & 0.24 \\
\hline CBT 8 & $\begin{array}{l}\text { MS ( } \gamma \text {-methacryloxypropyl trimethoxysilane })+ \text { GS }(\gamma- \\
\text { glycidoxypropyl triethoxysilane) }\end{array}$ & 0.28 \\
\hline CBT 9 & MS + GS + epoxy resin film former & 0.48 \\
\hline CBT 10 & APS + epoxy resin film former & 0.48 \\
\hline CBT 11 & GS + epoxy resin film former & 0.58 \\
\hline CBT 12 & MS + epoxy resin film former & 0.62 \\
\hline CBT 13 & GS + polyurethane film former & 0.50 \\
\hline CBT 14 & GS + epoxy resin film former & 1.05 \\
\hline
\end{tabular}


Table 2. Interphase adhesion properties of single-fiber model composites as a function of fiber diameter $\boldsymbol{d}_{\mathrm{f}}$ and embedded fiber length $\boldsymbol{l}_{\mathrm{e}}$

\begin{tabular}{llllll}
\hline System designation & \multicolumn{1}{c}{$\boldsymbol{d}_{\mathbf{f}}(\boldsymbol{\mu} \mathbf{m})$} & \multicolumn{1}{c}{$\boldsymbol{l}_{\mathbf{e}}(\boldsymbol{\mu} \mathbf{m})$} & \multicolumn{1}{c}{$\boldsymbol{G}_{\text {ic }}\left(\mathbf{J} / \mathbf{m}^{2}\right)$} & \multicolumn{1}{c}{$\boldsymbol{\tau}_{\mathbf{d}}(\mathbf{M P a})$} & \multicolumn{1}{c}{$\boldsymbol{\tau}_{\mathbf{f}}(\mathbf{M P a})$} \\
\hline CBT 1 & $12.9 \pm 1.7$ & $80.5 \pm 12.8$ & $2.6 \pm 1.7$ & $16.1 \pm 6.3$ & $11.6 \pm 5.7$ \\
CBT 1 & $12.7 \pm 2.0$ & $213.7 \pm 65.0$ & $3.4 \pm 2.1$ & $15.8 \pm 5.2$ & $4.5 \pm 2.8$ \\
CBT 2 & $18.7 \pm 1.7$ & $154.6 \pm 34.5$ & $13.1 \pm 11.2$ & $28.5 \pm 12.6$ & $21.5 \pm 12.2$ \\
CBT 2 & $17.8 \pm 1.3$ & $181.3 \pm 28.9$ & $22.9 \pm 25.8$ & $35.0 \pm 19.0$ & $19.8 \pm 12.0$ \\
CBT 4 & $15.5 \pm 2.6$ & $161.1 \pm 19.3$ & $19.4 \pm 16.6$ & $35.1 \pm 14.6$ & $13.6 \pm 5.8$ \\
CBT 7 & $13.7 \pm 2.1$ & $170.3 \pm 7.3$ & $6.1 \pm 2.3$ & $20.4 \pm 5.2$ & $3.9 \pm 1.5$ \\
CBT 8 & $12.9 \pm 2.8$ & $193.8 \pm 45.8$ & $8.2 \pm 7.0$ & $22.9 \pm 10.4$ & $5.5 \pm 3.4$ \\
CBT 8 & $14.1 \pm 2.4$ & $211.5 \pm 67.2$ & $12.4 \pm 7.6$ & $27.8 \pm 8.8$ & $3.0 \pm 1.1$ \\
CBT 9 $*$ & $13.1 \pm 2.3$ & $164.5 \pm 41.0$ & $15.1 \pm 9.8$ & $33.2 \pm 11.2$ & $10.8 \pm 6.7$ \\
CBT 9 & $13.8 \pm 1.7$ & $203.5 \pm 23.9$ & $15.0 \pm 7.6$ & $31.3 \pm 8.2$ & $3.0 \pm 0.8$ \\
CBT 10 & $12.2 \pm 1.4$ & $216.7 \pm 62.4$ & $25.1 \pm 21.8$ & $41.4 \pm 16.3$ & $20.4 \pm 8.3$ \\
CBT 1 & $12.5 \pm 1.8$ & $214.8 \pm 46.1$ & $10.8 \pm 9.1$ & $27.4 \pm 10.6$ & $11.6 \pm 6.2$ \\
CBT 12 & $13.2 \pm 1.4$ & $210.3 \pm 44.7$ & $19.7 \pm 15.6$ & $35.9 \pm 13.7$ & $16.2 \pm 8.8$ \\
CBT 13 & $12.7 \pm 2.0$ & $212.1 \pm 54.1$ & $10.3 \pm 6.7$ & $27.3 \pm 9.2$ & $12.9 \pm 7.0$ \\
CBT 14 & $13.4 \pm 2.1$ & $217.9 \pm 37.9$ & $19.7 \pm 19.2$ & $35.3 \pm 17.0$ & $17.4 \pm 11.7$ \\
\hline
\end{tabular}

* Conditions of polymerization: Heating $80^{\circ} \mathrm{C}$ under argon purge gas for $30 \mathrm{~min}$; rapid heating to $190^{\circ} \mathrm{C}, 30$ min polymerization at $190^{\circ} \mathrm{C}$. 
Table 3. Gel permeation chromatography (GPC) determination of molecular weights $\left(M_{n}, M_{w}\right)$

\begin{tabular}{llll}
\hline System & $\begin{array}{l}\text { Conversion } \\
(\%)\end{array}$ & $\begin{array}{l}\mathbf{M}_{\mathbf{n}} \\
\left(\mathrm{x} \mathrm{11} 0^{-3} \mathrm{~g} / \mathrm{mol}\right)\end{array}$ & $\begin{array}{l}\mathbf{M}_{\mathbf{w}} \\
\left(\mathrm{x} \mathrm{10} 0^{-3} \mathrm{~g} / \mathrm{mol}\right)\end{array}$ \\
\hline CBT-1 & 83.6 & 38.3 & 96.8 \\
CBT-2 & 91.3 & 42.2 & 111.2 \\
CBT-8 & 85.7 & 46.8 & 120.2 \\
CBT-9 & 90.3 & 38.1 & 99.8 \\
CBT-10 & 87.0 & 33.7 & 83.8 \\
CBT-11 & 88.9 & 35.0 & 84.7 \\
CBT-12 & 79.3 & 32.6 & 83.3 \\
CBT-13 & 88.2 & 38.5 & 95.5 \\
CBT-14 & 85.4 & 33.6 & 84.5 \\
\hline
\end{tabular}


Table 4. Summarized data of interfacial strength $\tau_{d}$, critical interfacial energy release rate $G_{i c}$, roughness $R_{a}$ before and after pull-out, isoelectric points IEP and molecular weights $M n, M w$

\begin{tabular}{|c|c|c|c|c|c|c|c|}
\hline $\begin{array}{l}\text { System } \\
\text { designation }\end{array}$ & $\overline{\tau_{d}(\mathrm{MPa})}$ & $G_{i c}\left(\mathbf{J} / \mathbf{m}^{2}\right)$ & $\begin{array}{c}R_{a}(\mathrm{~nm}) \\
\text { (virgin } \\
\text { fiber) }\end{array}$ & $\begin{array}{c}R_{a}(\mathrm{~nm}) \\
\text { (pulled out } \\
\text { fiber) }\end{array}$ & $\begin{array}{c}E P \\
\text { (pH- } \\
\text { Value) }\end{array}$ & $\begin{array}{l}M_{\boldsymbol{n}} \\
\left(\mathrm{x} 10^{-3}\right. \\
\mathrm{g} / \mathrm{mol})\end{array}$ & $\begin{array}{l}M_{\boldsymbol{w}} \\
\left(\mathrm{x} 10^{-3}\right. \\
\mathrm{g} / \mathrm{mol})\end{array}$ \\
\hline CBT 1 & $15.8 \pm 5.2$ & $3.4 \pm 2.1$ & $2.1 \pm 1.3$ & $8.2 \pm 3.3$ & $<3.0$ & 38.3 & 96.8 \\
\hline CBT 2 & $35.0 \pm 19.0$ & $22.9 \pm 25.8$ & $1.8 \pm 1.0$ & $27 \pm 21.5$ & 4.0 & 42.2 & 111.2 \\
\hline CBT $4 *$ & $35.1 \pm 14.6$ & $19.4 \pm 16.6$ & $4.5 \pm 2.0$ & $85.3 \pm 6.1$ & 8.3 & - & - \\
\hline CBT $7 *$ & $20.4 \pm 5.2$ & $6.1 \pm 2.3$ & $3.4 \pm 3.1$ & $39.3 \pm 17.2$ & 9.3 & - & - \\
\hline CBT 10 & $41.4 \pm 16.3$ & $25.1 \pm 21.8$ & $2.3 \pm 0.7$ & $27.0 \pm 20.4$ & 7.8 & 33.7 & 83.8 \\
\hline CBT 11 & $27.4 \pm 10.6$ & $10.8 \pm 9.1$ & $15.4 \pm 4.5$ & $30.2 \pm 12.8$ & 3.2 & 35.0 & 84.7 \\
\hline CBT 12 & $35.9 \pm 13.7$ & $19.7 \pm 15.6$ & $8.8 \pm 4.5$ & $12.1 \pm 4.6$ & $<3.0$ & 32.6 & 83.3 \\
\hline CBT 13 & $27.3 \pm 9.2$ & $10.3 \pm 6.7$ & $8.5 \pm 9.4$ & $12.2 \pm 4.4$ & 3.8 & 38.5 & 95.5 \\
\hline CBT 14 & $35.3 \pm 17.0$ & $19.7 \pm 19.2$ & $25.5 \pm 9.6$ & $28.9 \pm 10.5$ & $<3.0$ & 33.6 & 84.5 \\
\hline
\end{tabular}




\section{ACCEPTED MANUSCRIPT}

\section{Figure Captions}

Fig. 1. Schematic of specimen preparation of single fibers for AFM surface topography.

Fig. 2. Schematic of specimen preparation for single fiber pull-out test.

Fig. 3. Zeta potential vs. $\mathrm{pH}$ for glass fibers due to acidic and/or basic groups created by the sizings. (a) IEP values are around 3 4 for CBT 1,2,11-14 systems. (b) IEP values are around 8 9 for CBT 4, 7, 10 systems.

Fig. 4. AFM topography images of (a) CBT 1, (b) CBT 2, (c) CBT 4 and (d) CBT 7 glas s fiber surfaces.

Fig. 5. AFM topography images of (a) CBT 10, (b) CBT 11,(c) CBT 12 and (d) CBT 14 glass fiber surfaces.

Fig. 6. Comparison of image mean roughness, $R_{a}$ (a) and maximum height roughness, $R_{\max }(\mathrm{b})$ with standard deviation on $4 \times 4 \mu \mathrm{m}$ of ' $\mathrm{CBT}$ ' glass fiber surfaces.

Fig. 7. AFM topography images of (a) CBT 1, (b) CBT 2, (c) CBT 4 and (d) CBT 7 glass fiber surfaces after pull-out.

Fig. 8. AFM topography images of (a) CBT 10 (b) CBT 11, (c) CBT 12 and (d) CBT 14 glass fiber surfaces after pull-out.

Fig. 9. Comparison of image mean roughness, $R_{a}$ on surfaces of 'CBT' sized model fibers and fracture surfaces after pull-out tests. The insert shows the variation (\%) of roughness before and after pull-out. 


\section{ACCEPTED MANUSCRIPT}

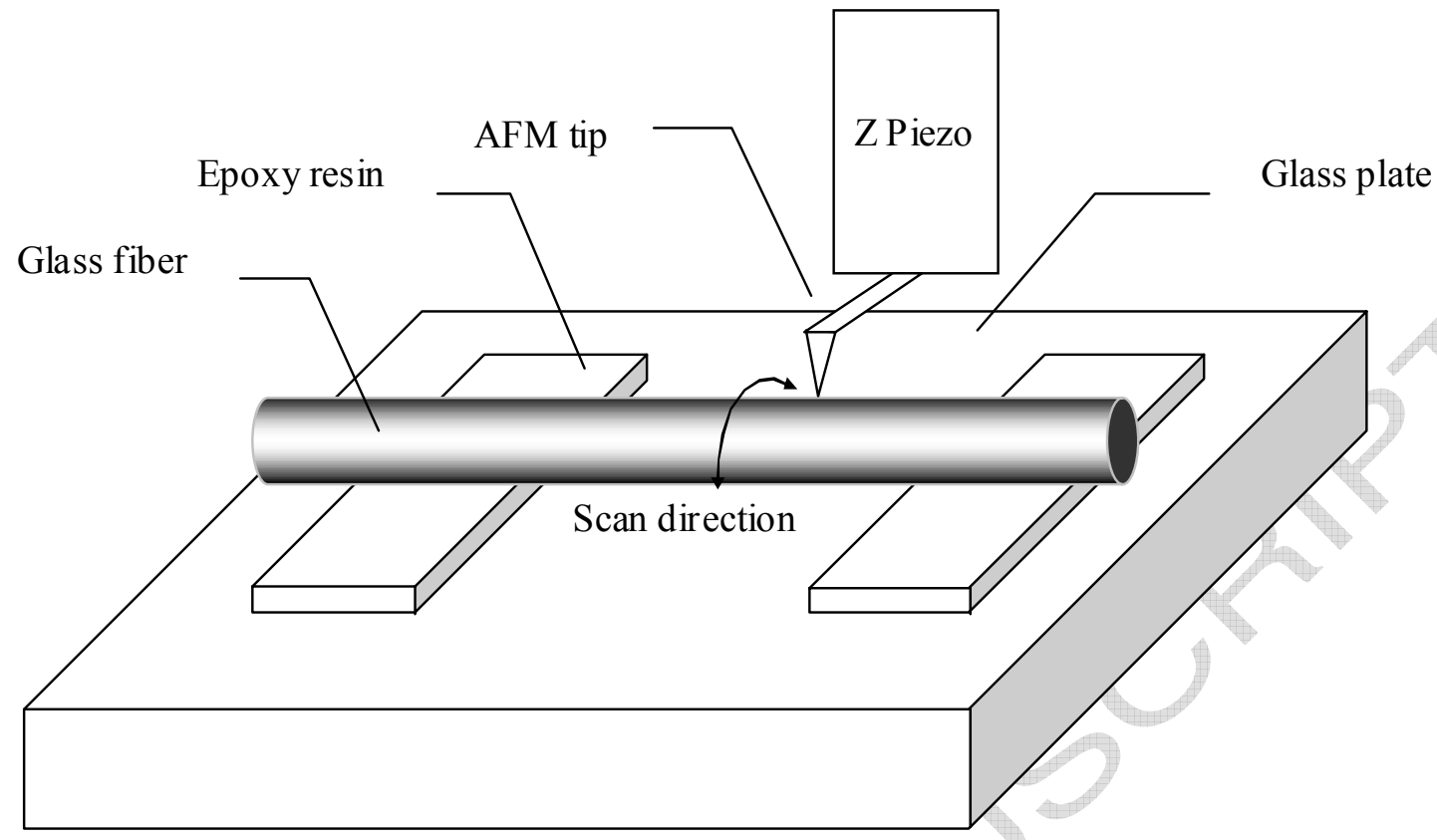

Fig. 1. Schematic of specimen preparation of single fibers for AFM surface topography.

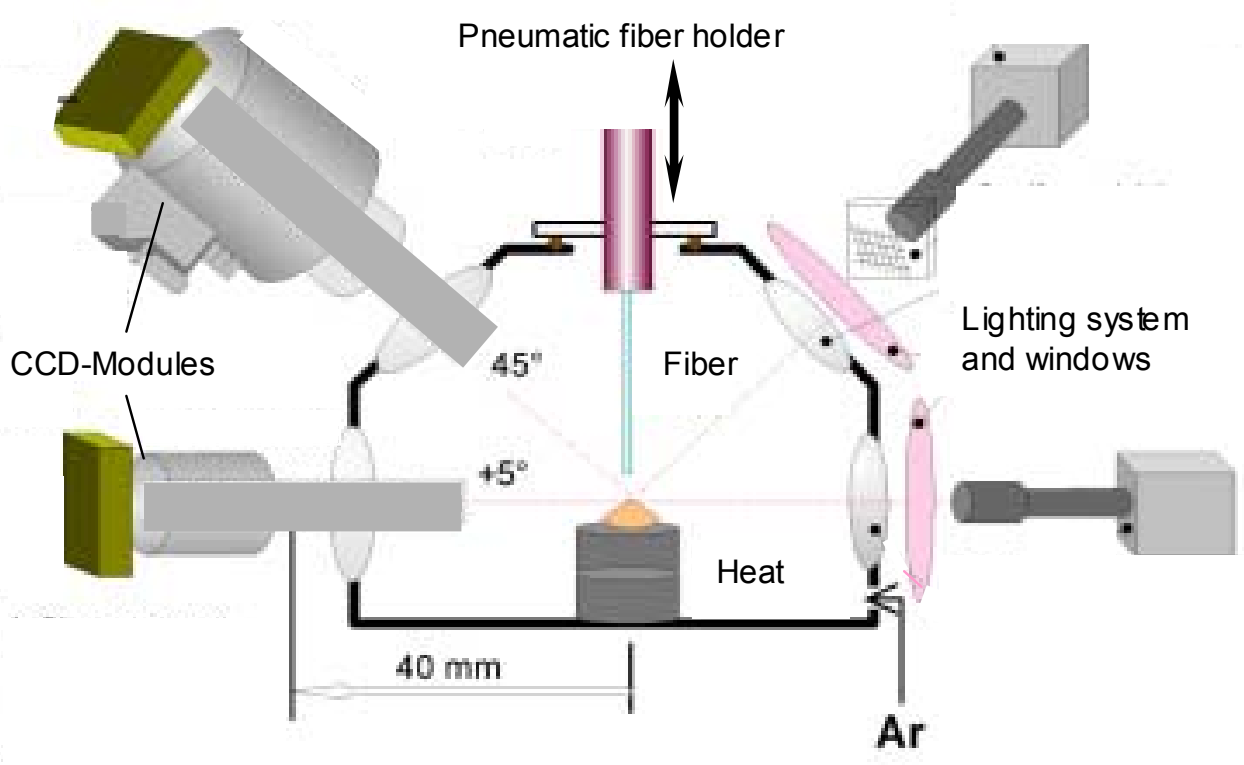

Fig. 2. Schematic of specimen preparation for single fiber pull-out test. 


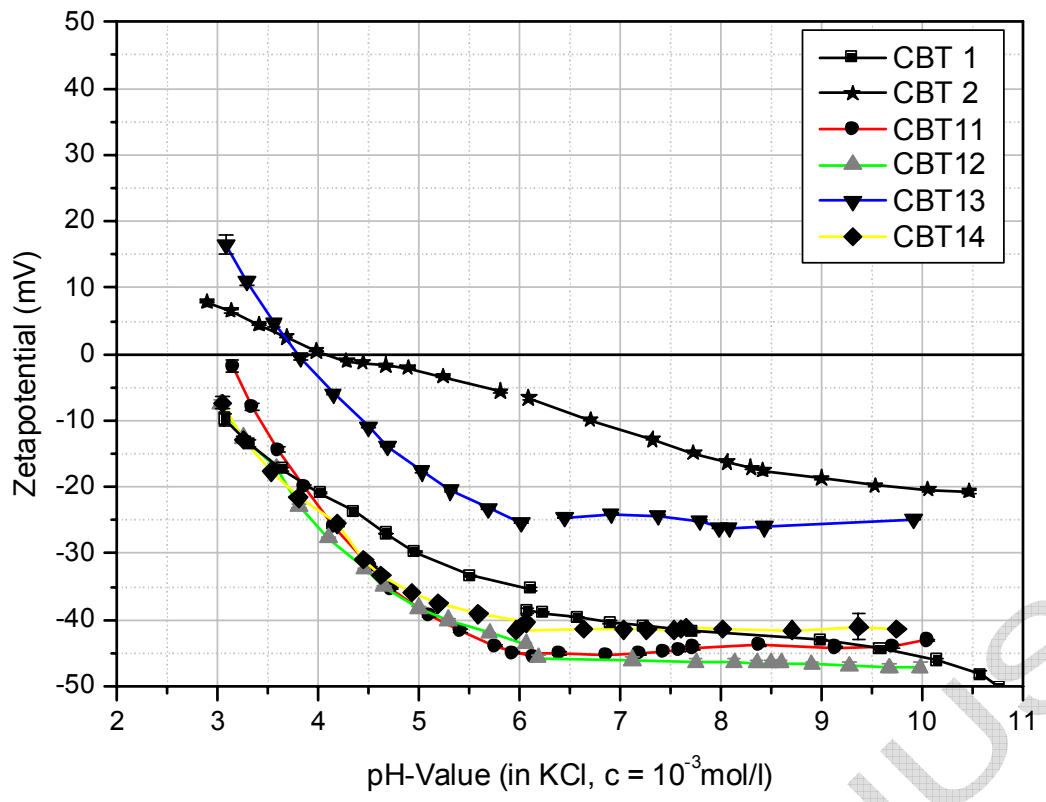

(a)

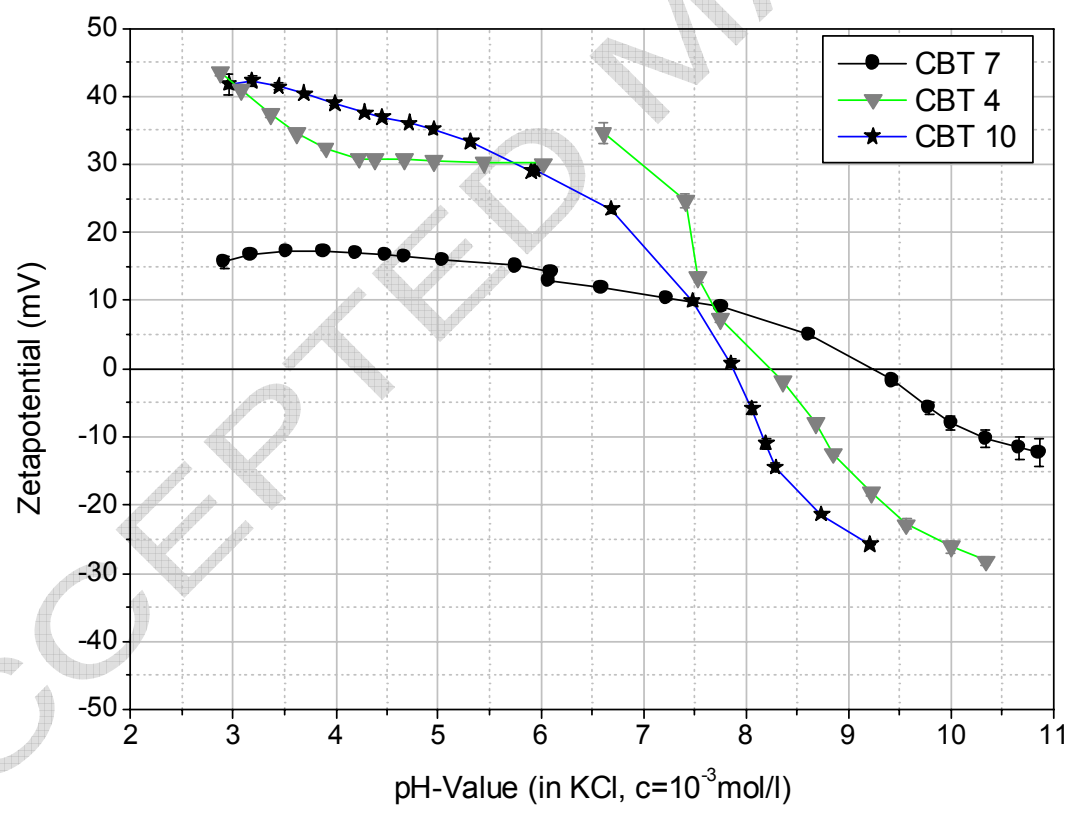

(b)

Fig. 3. Zeta potential vs. $\mathrm{pH}$ for glass fibers due to acidic and/or basic groups created by the sizings. (a) IEP values are around 3 4 for CBT 1,2,11-14 systems. (b) IEP values are around 8 9 for CBT 4, 7, 10 systems. 


\section{ACCEPTED MANUSCRIPT}

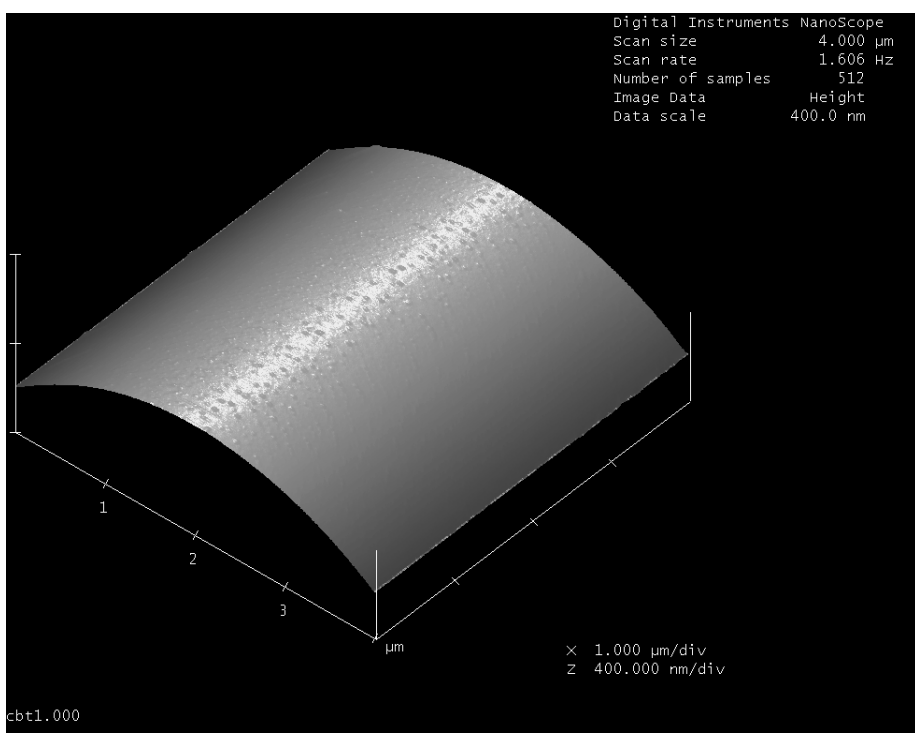

(a)

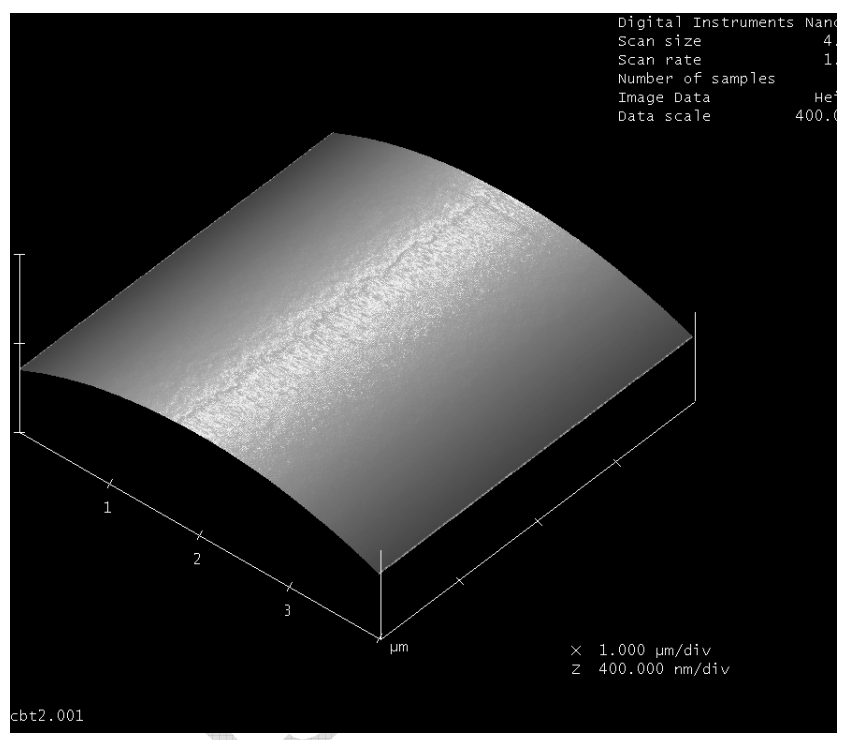

(b)

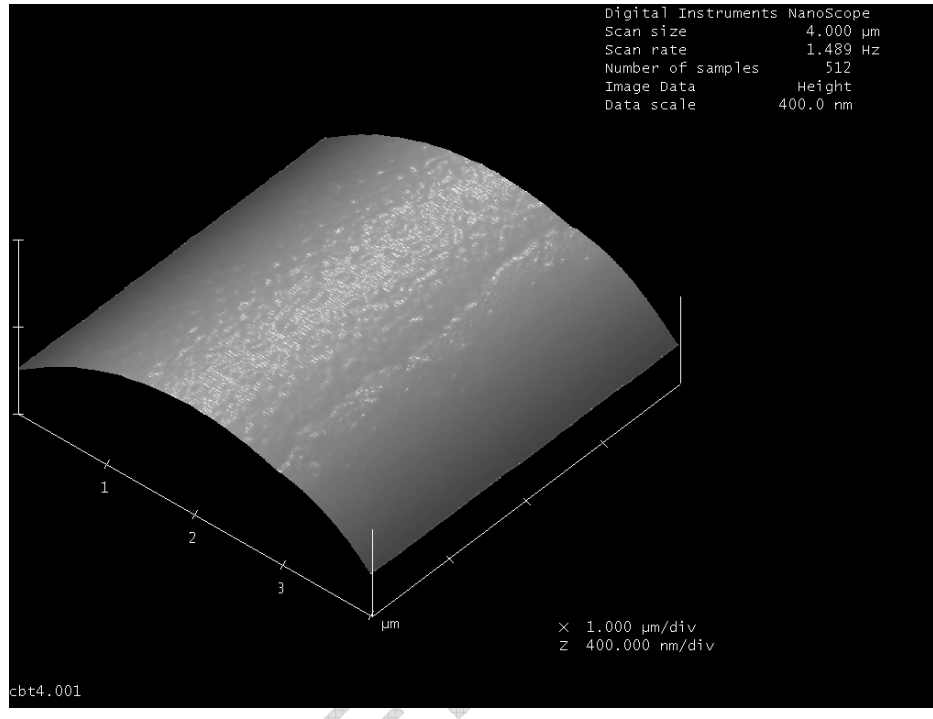

(c)

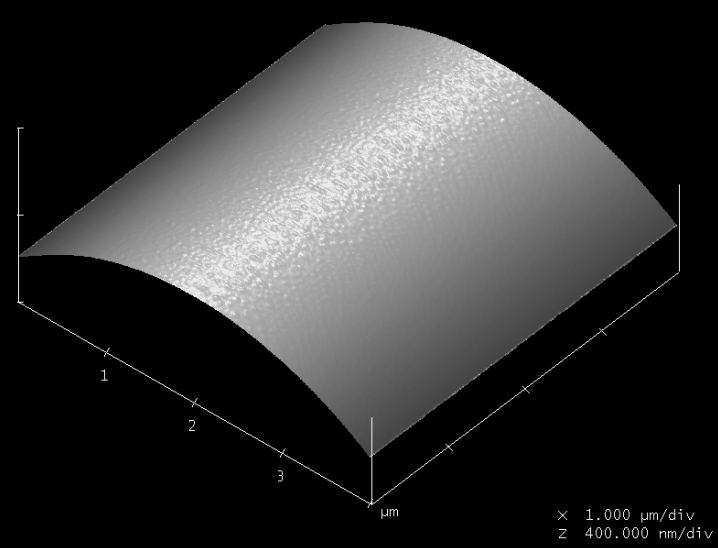

bt7.002

(d)

Fig. 4. AFM topography images of (a) CBT 1, (b) CBT 2, (c) CBT 4 and (d) CBT 7 glass fiber surfaces. 


\section{ACCEPTED MANUSCRIPT}

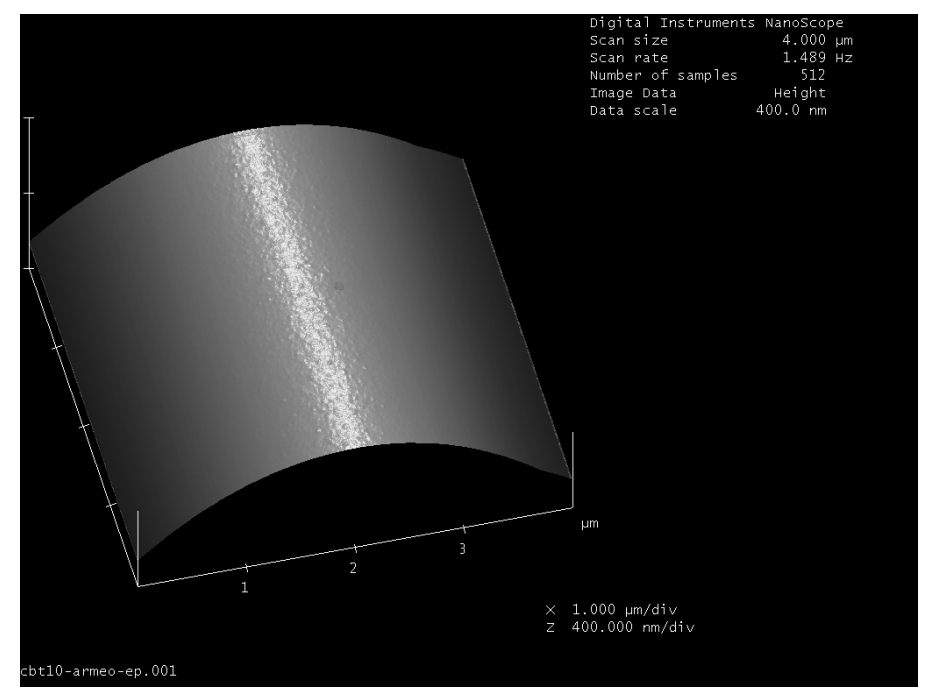

(a)

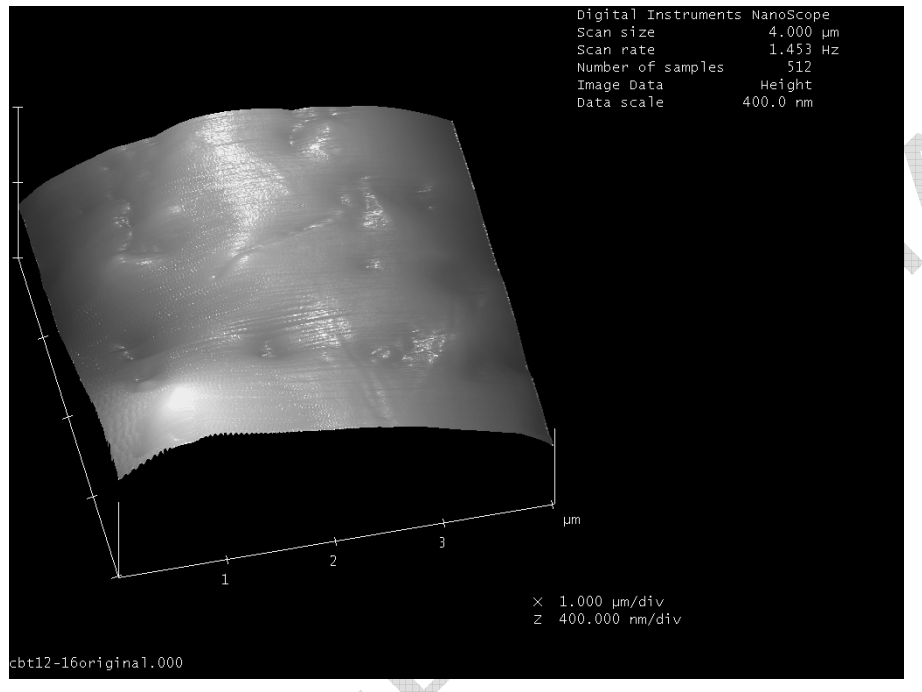

(c)

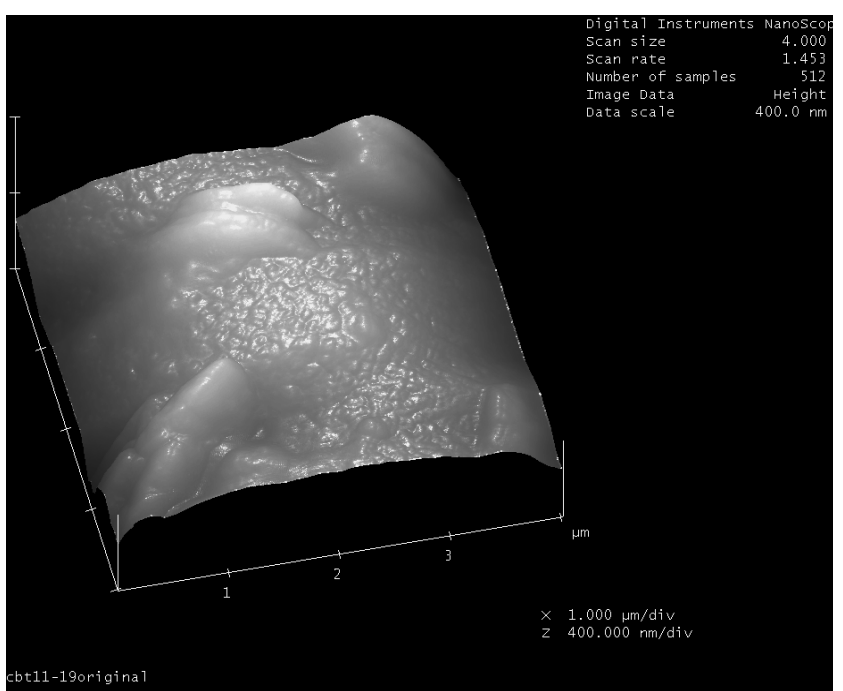

(b)

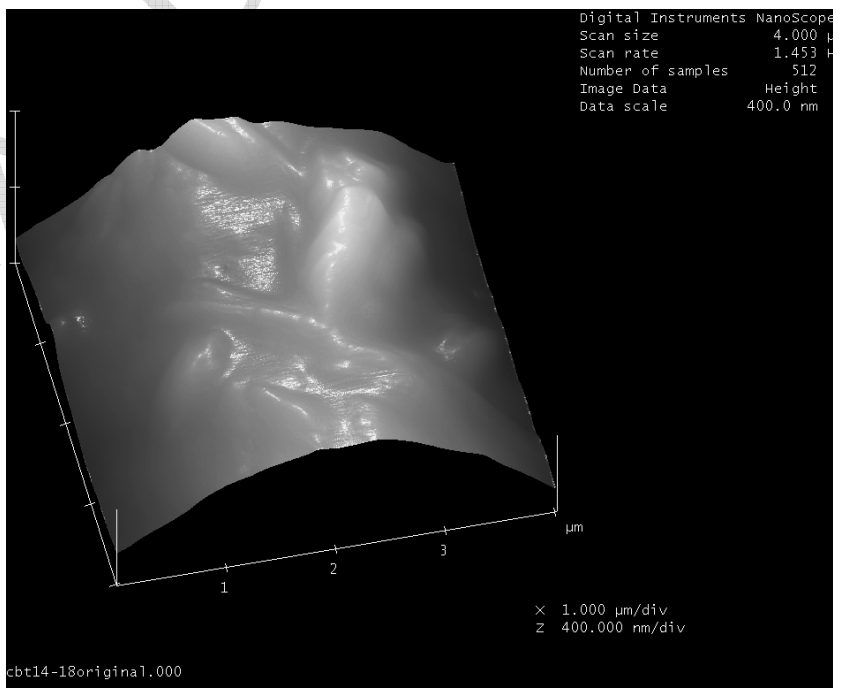

(d)

Fig. 5. AFM topography images of (a) CBT 10, (b) CBT 11, (c) CBT 12 and (d) CBT 14 glass fiber surfaces. 


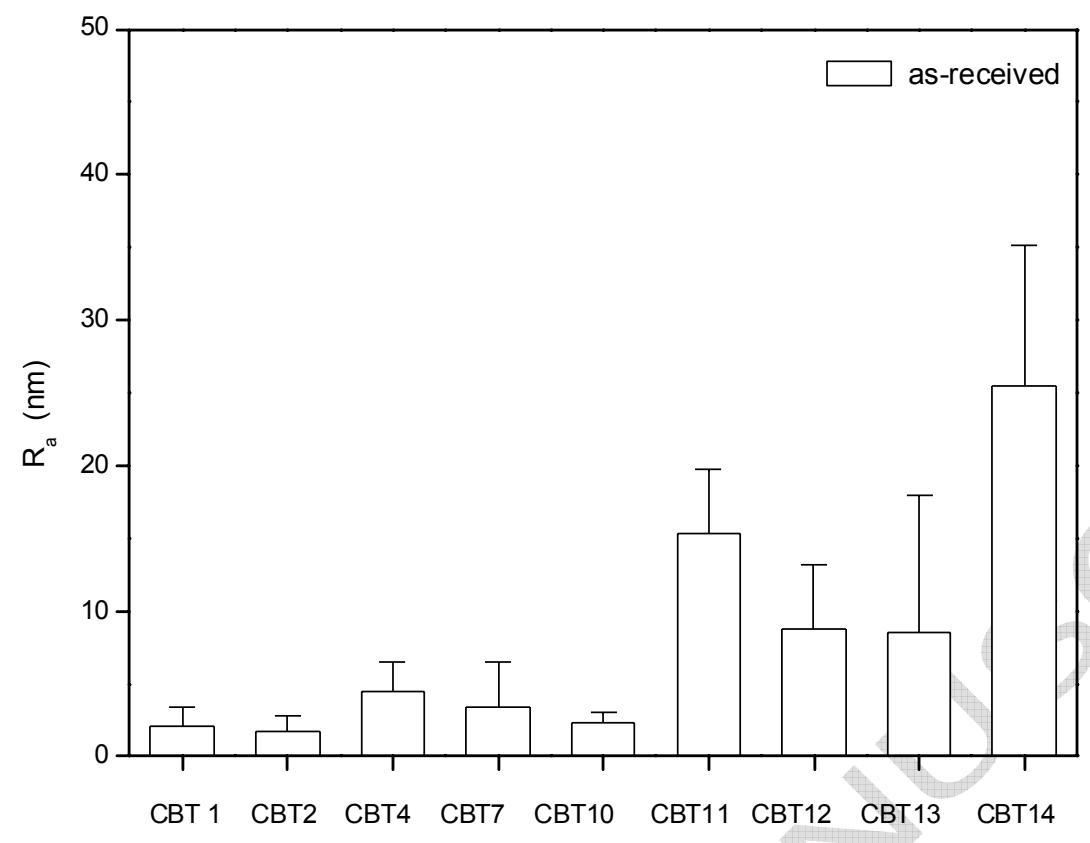

(a)

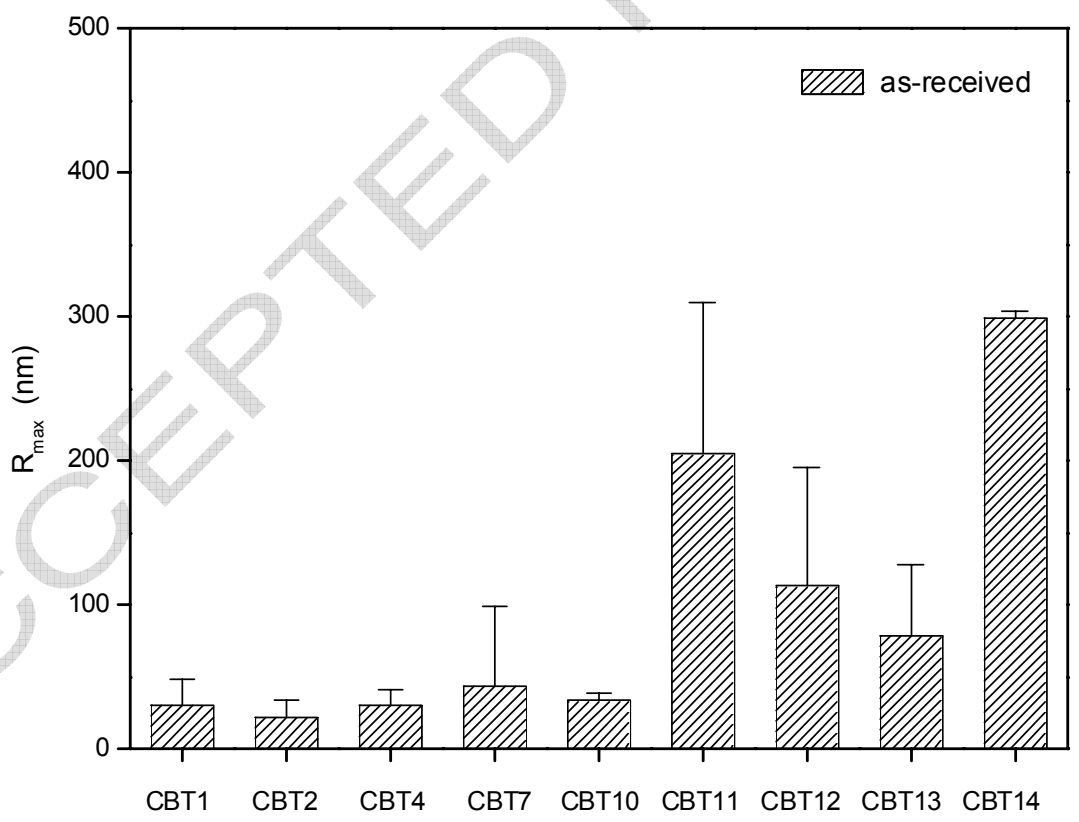

(b)

Fig. 6. Comparison of image mean roughness, $R_{a}$ (a) and maximum height roughness, $R_{\max }$ (b) with standard deviation on $4 \times 4 \mu \mathrm{m}$ of ' $\mathrm{CBT}$ ' glass fiber surfaces. 


\section{ACCEPTED MANUSCRIPT}

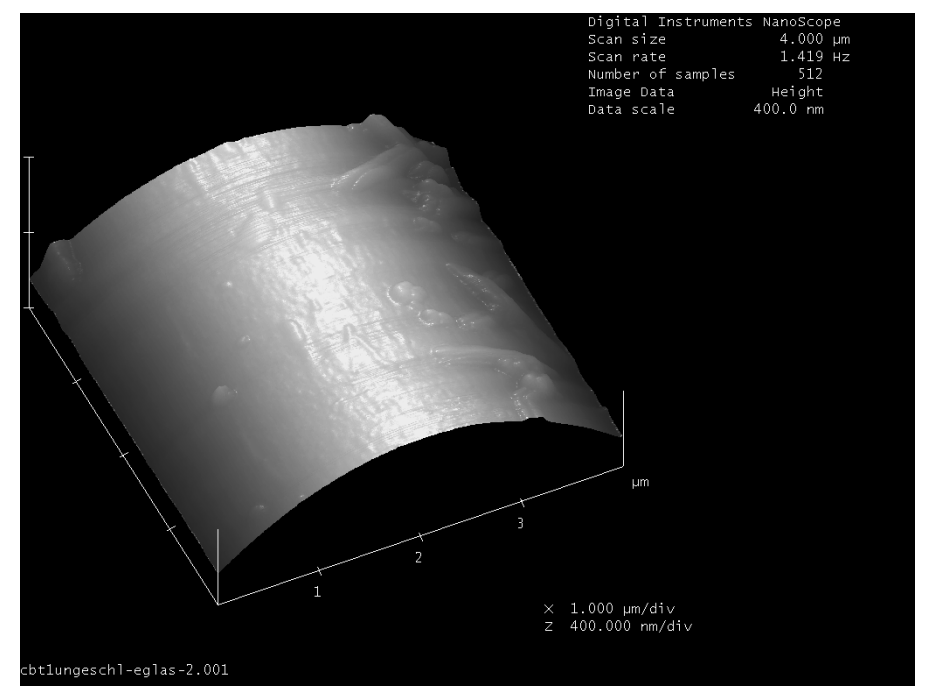

(a)

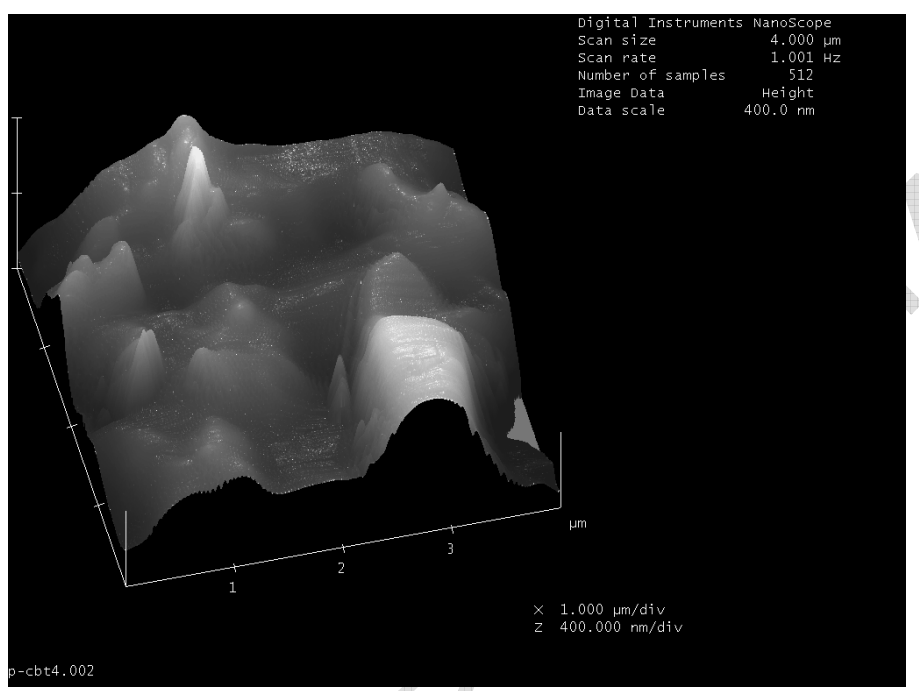

(c)

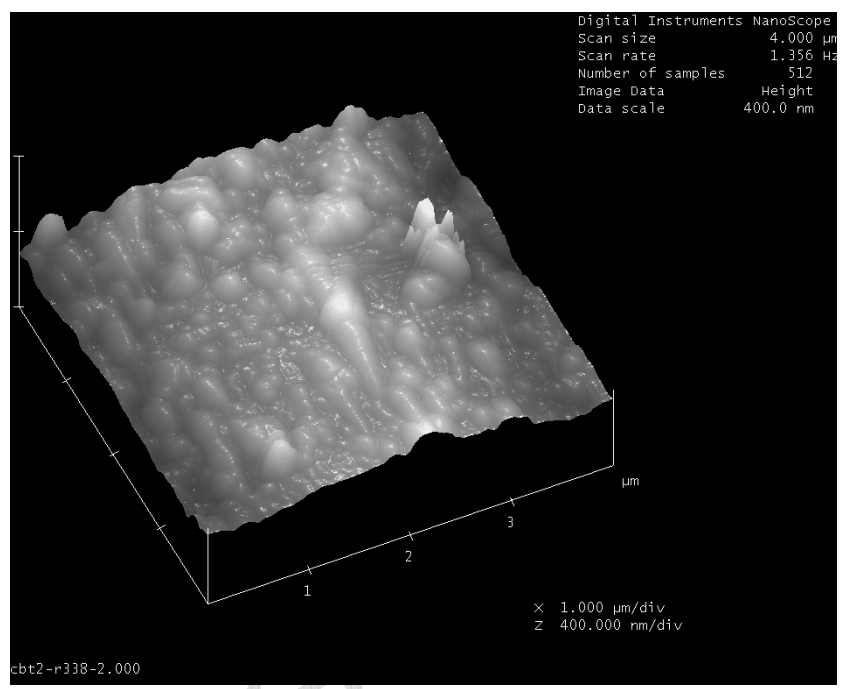

(b)

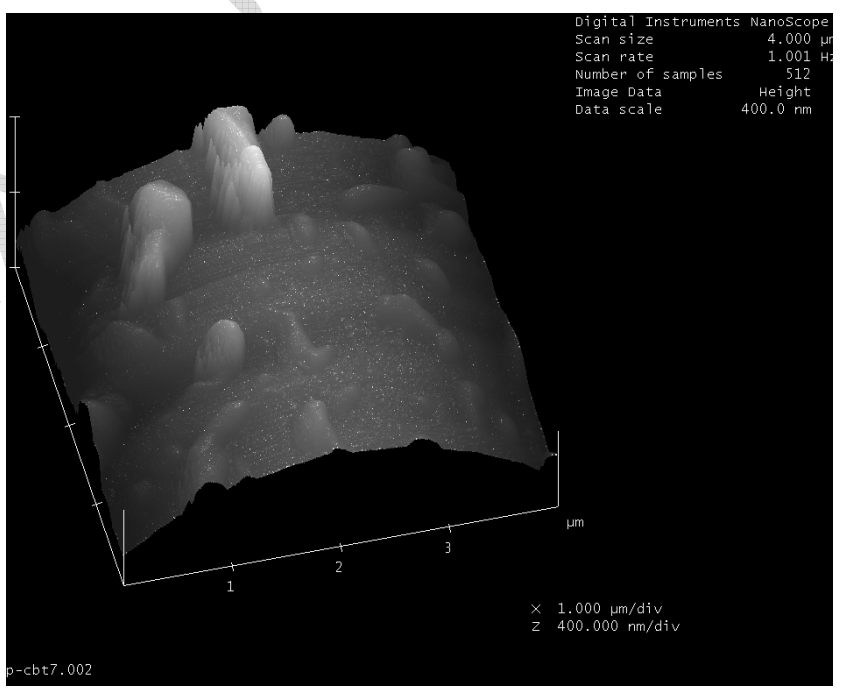

(d)

Fig. 7. AFM topography images of (a) CBT 1, (b) CBT 2, (c) CBT 4 and (d) CBT 7 glass fiber surfaces after pull-out. 


\section{ACCEPTED MANUSCRIPT}

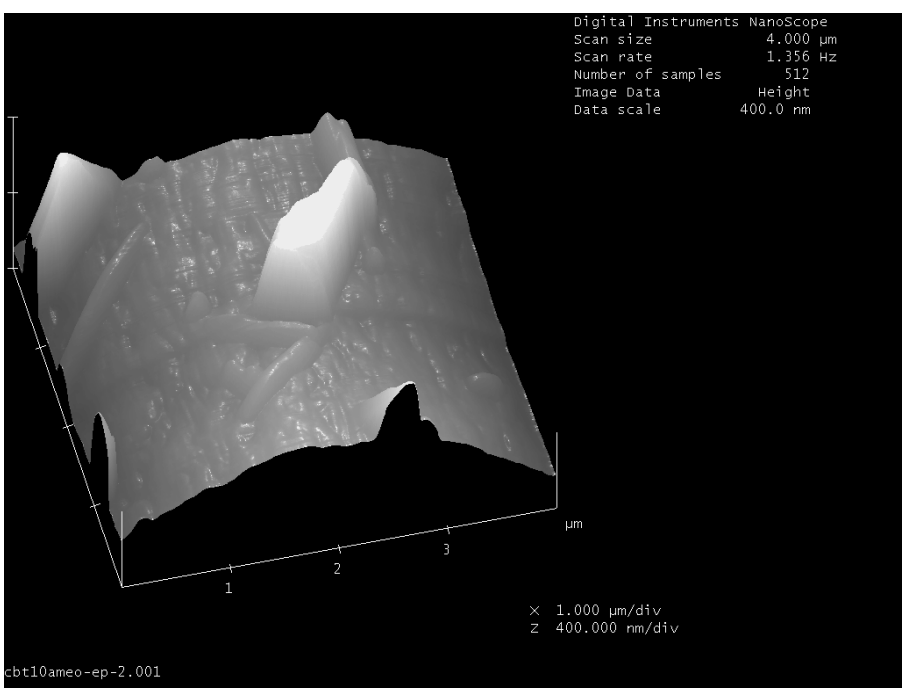

(a)

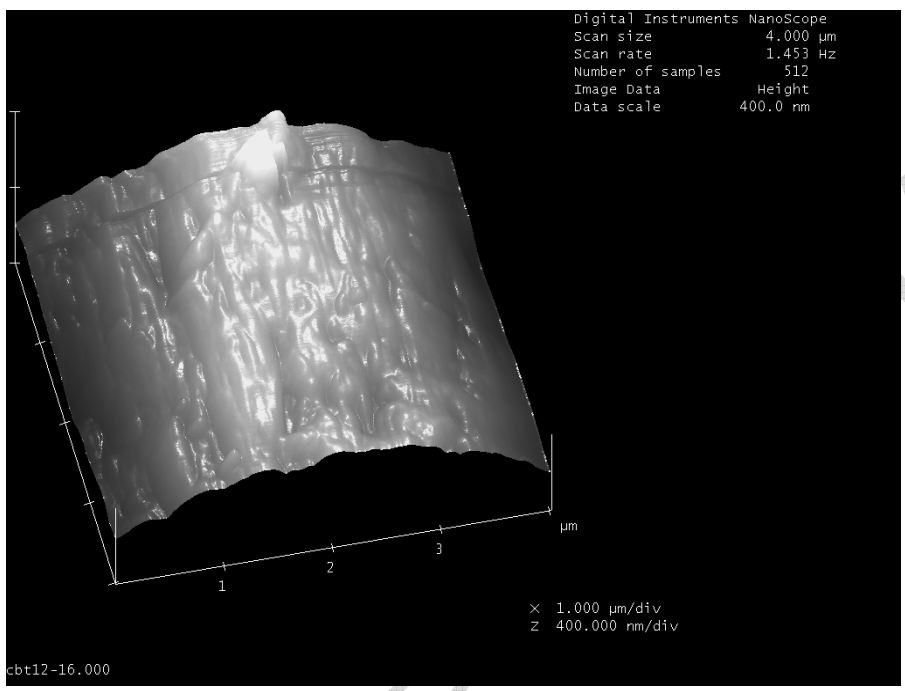

(c)

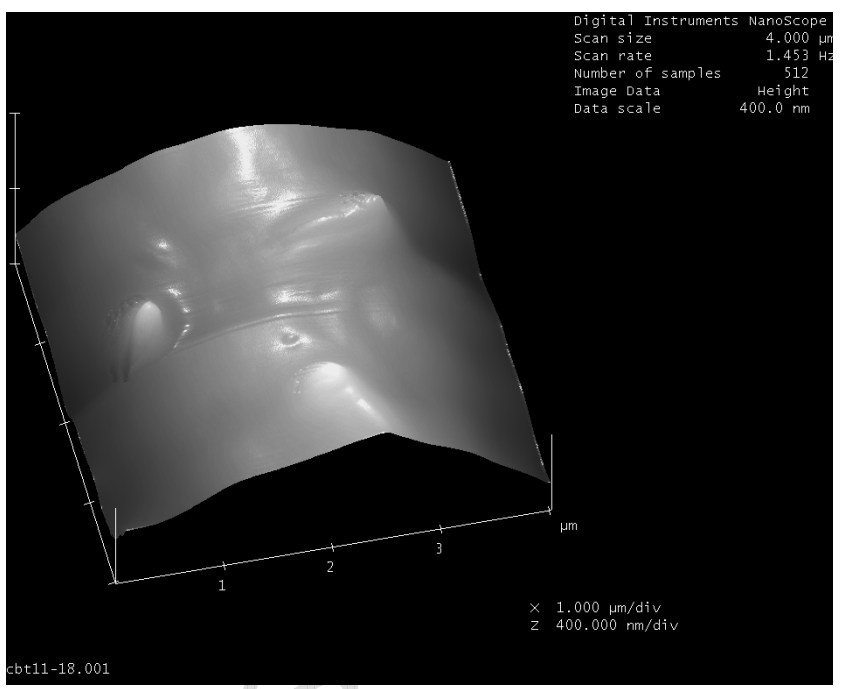

(b)

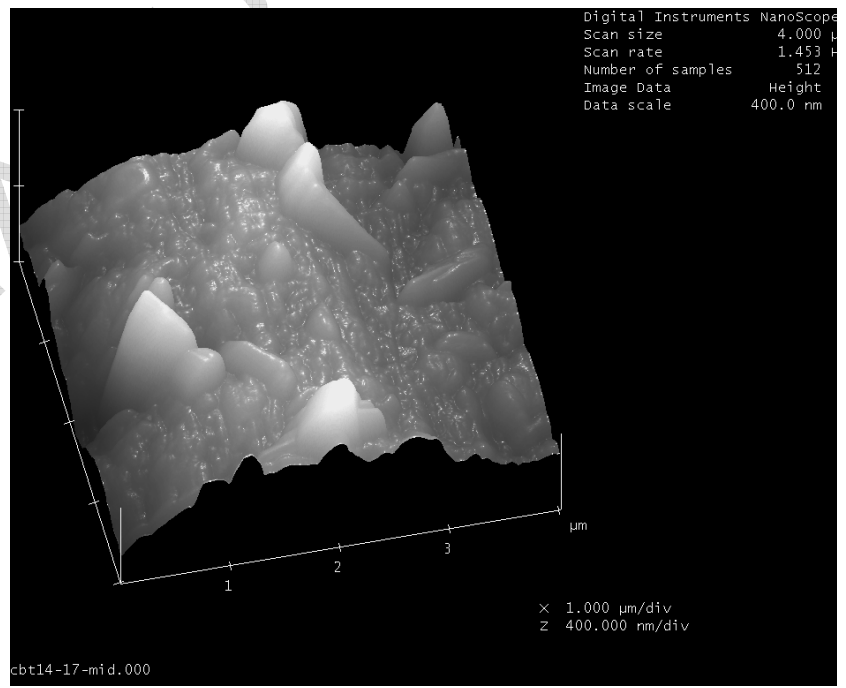

(d)

Fig. 8. AFM topography images of (a) CBT 10 (b) CBT 11, (c) CBT 12 and (d) CBT 14 glass fiber surfaces after pull-out. 


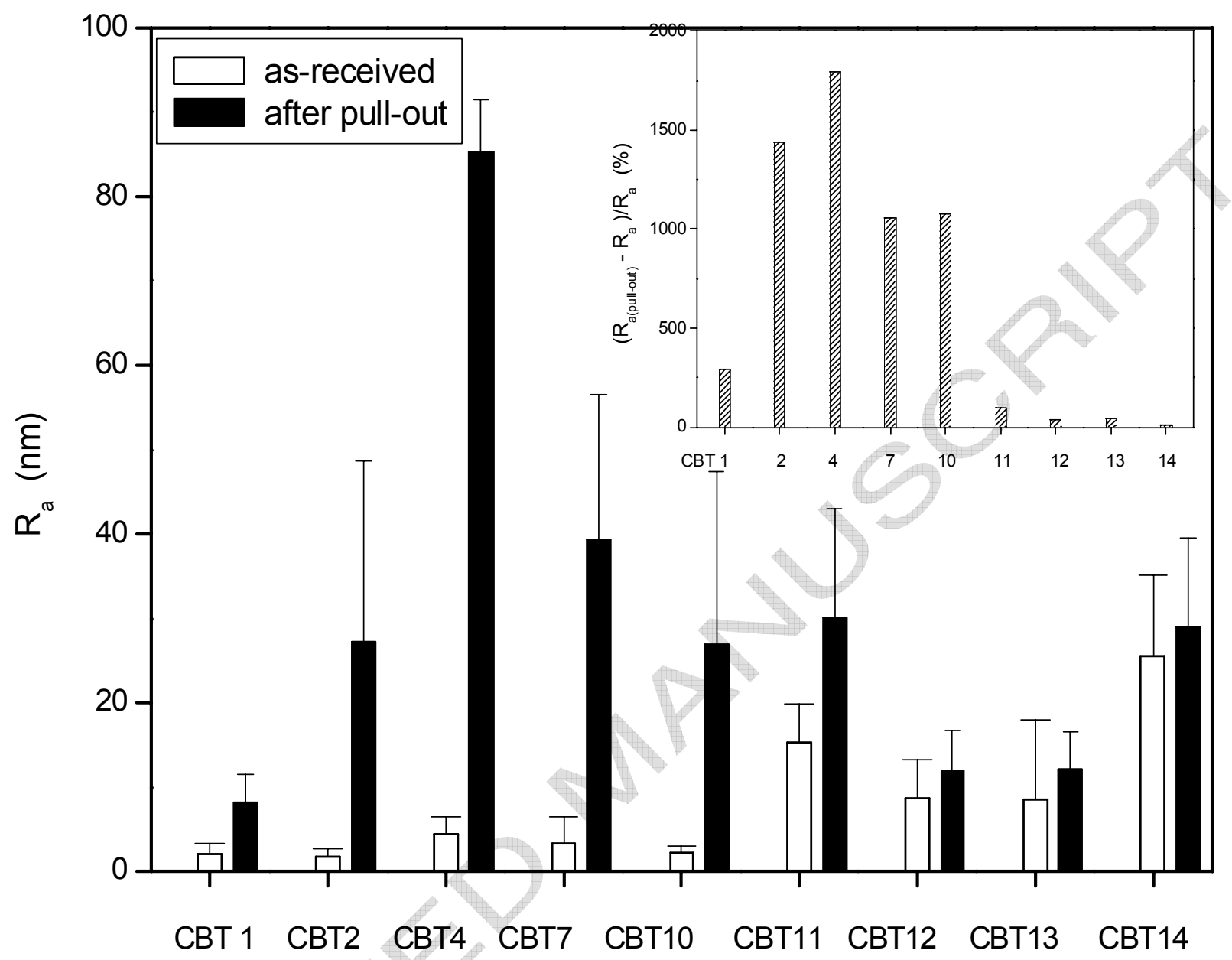

Fig. 9. Comparison of image mean roughness, $R_{a}$ on surfaces of 'CBT' sized model fibers and fracture surfaces after pull-out tests. The insert shows the variation (\%) of roughness before and after pull-out. 